\title{
Effect of Climate Change on Rice Production: A Case of Six VDCs in Jumla District
}

\author{
Sudha Sapkota ${ }^{1}$, Mina Nath Paudel $^{2}$, Naresh Singh Thakur ${ }^{1}$, \\ Megh Bahadur Nepali ${ }^{1}$ and Reshma Neupane ${ }^{3}$ \\ ${ }^{1}$ Socioeconomics and Agricultural Research Policy Division \\ ${ }^{2}$ Outreach Research Division and ${ }^{3}$ Agronomy Division, NARC, Khumaltar, Lalitpur \\ e-mail:sudhanepal@gmail.com
}

\begin{abstract}
Rice (Oryza sativa L.) is a staple crop of Nepal and is directly associated with ample water and minimum fluctuation of temperature that could affect on its production. Jumla is the unique place where rice is cultivated in the highest altitude $(3000 \mathrm{~m})$ in the world. To find out changes in rice production due to climatic effect, six VDCs of Jumla were chosen for the study. Household survey, participatory rapid appraisal, farmers' group discussions and desk review were used for collecting data. Rice varieties Chandannath- 1 andChandannath- 3 were disseminated by the formal seed system with the aim of increasing rice productivity. Despite the replacement of local varieties by improved ones the production trend seems to be stagnant. One of the factors on stagnant of rice production in Jumla is due to the lack of desirable variety with genetic traits of early maturity, less nutrient requirement compared to Jumli Marshi to cope up with the climate congruently supporting to cultural practices regarding the unique rice production systems of Jumla.
\end{abstract}

Key words: climate change, rice production, highest altitude, seed

\section{Introduction}

Jumla is a unique place in Nepal where rice is cultivated in the highest altitude in the world and the specific place Chhumchour (3000 $\mathrm{m}$ ) has got the priviledge of rice cultivation in the highest altitude in the world (Paudel \& Thakur, 2009). Climate change itself is constituted changes in the form of soil, water and air over a period of time that range from decades to millions of years. Despite technological advances on crop varieties, genetically modified organisms, and irrigation systems, weather is still a key factor in agricultural productivity and soil properties. There are some evidences that climate has been changing in Nepal. The temperature has been increased by $1.8^{\circ} \mathrm{C}$ during the last 32 years and the average temperature increase was recorded $0.06^{0} \mathrm{C}$ per year. As well the rainfall pattern is also experienced as inconsistent with the higher intensities of rain and less number of rainy days (Malla, 2008). Early maturity of the crops due to increased temperature helped increase the number of crops per year (Raut, 2010). The effect of climate on agriculture is related to variability in local climates rather than in global climate patterns. The earth's average surface temperature has increased by $1^{\circ} \mathrm{F}$ in just over the last century. Consequently, agronomists consider any assessment has to be individually considered for each of the local area. This is because each component of living being is tied with climate (Malla, 2008). Not only the living beings but also the metamorphosis of non-living things also depend on climate over a long period. The existence of human being is directly linked with the availability of edible food material in the world.

Climatic parameters such as rainfall, temperature, humidity affect plants in their life cycle starting from vegetative to reproductive stages. Therefore, to find out the existing scenario of rice production due to change in climate over the periods was undertaken in the study.

\section{Methodology}

Six VDCs of Jumla districts namely Chandannath, Mahat, Talium, Kartikswami, Dillichour, Narakot were 
selected for this study. Five house households from each VDC were surveyed. Participatory rapid appraisal (PRA) and farmers' group discussion (FGD) were held for collecting primary information regarding the rice production. Literature reviews were carried out to collect secondary data. Farmers were selected randomly to understand the system of rice growing. Data were analyzed by using SPSS and the excel packages.

\section{Results and Discussion \\ Land profile}

The total area of Jumla district is 2, 54,365ha. Of this, 39,486 ha has been used for agricultural purpose. Rice is grown in 3009 ha. Soils of the surveyed sites were generally shallow to deep and moderately drained. The topography is gently sloppy to rolling and lying in the lap of high mountain region (2200-3000 m). Surface soil and sub-surface soils are dominantly coarse (sandy loam) and are acidic to moderately alkaline in reaction (ARS, 2009).

\section{Rice in Jumla}

During 2007/2008, rice in Jumla was cultivated in 2850 ha with a production of $4844 \mathrm{mt}$ having productivity of 1.7 t/ha (ARS, 2009). Jumli Marshi, a local rice popularly grown in Jumla has productivity of $60 \%$ of the national productivity of rice (2.7 mt/ha). In Jumla, Nepal Agricultural Research Council (NARC) and Department of Agriculture (DoA) have distributed seeds of two improved varieties of rice namely Chandanath-1 and Chandanath-3. However, farmers still prefer to grow Jumli Marshi, popular variety grown in Jumla valley since long back. Now Chandanath-3 is becoming popular and farmers are growing this variety along with and Jumli Marshi. Trend of rice production in Jumla has been shown in Fig. 1.

It is depicted that the production and area of rice have been increasing despite constant productivity over a decade (1999/00 to 2008/09). It is anticipated that improved rice production practice in Jumla could not address the problem of hunger and food shortage in the area. Even if all area suitable for rice is cultivated for this crop this will be sufficient to feed only 33\% period of the year. After that $66 \%$ of the year needs to supplement food to the populace in Jumla and this has been met through the rice supplied from Nepal
Food Corporation (NFC). Per capita availability of rice in 2010 in six village development committees (VDCs) has been indicated that per capita availability of rice in the surveyed VDCs ranged from $5-35 \mathrm{~kg} / \mathrm{head}$ (Fig. 2).

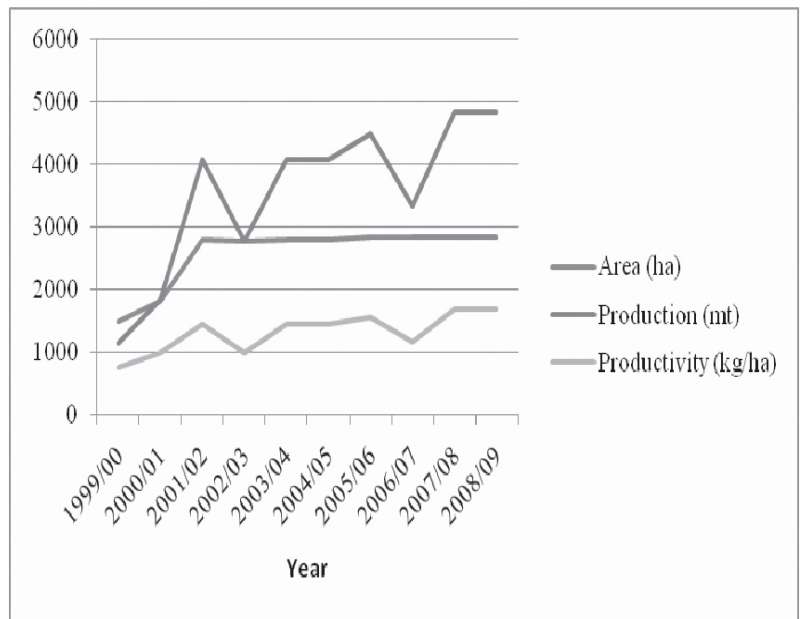

Fig. 1. Trend of rice production in Jumla Source: Statistical yearbook of MoAC, Nepal

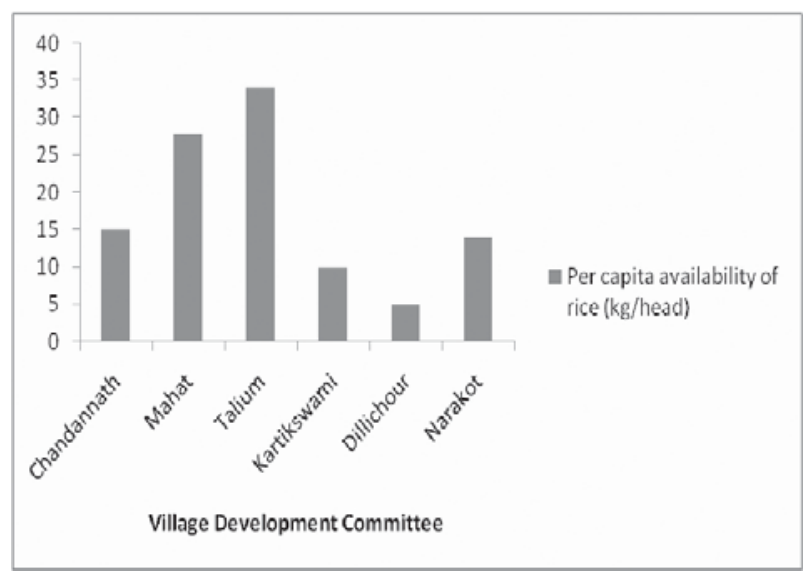

Fig. 2. Per capita availability of rice in surveyed village development committees of Jumla in 2010

Government of Nepal has been providing rice to feed hungry mouth in Jumla however, it is not fulfilling the ever increasing demand of rice in the region.

\section{Climatic factors affecting crop yield Soil degradation}

Soil degradation denotes decline in soil quality due to many factors including natural and anthropogenic activities. Anthropogenic activities are human related 
activities whereas natural activities consist of crusting, compaction, erosion, nutrient depletion, leaching, acidification, salinization, depletion of soil organic matter and reduction in soil biodiversity.

Agricultural intensification raises concerns about soil erosion, plant nutrient depletion, water quality and soil organic matter depletion (Garner \& Gerrard 2003; cited by Raut, 2010). These factors are particularly relevant to the hilly regions of Nepal which are intensively cultivated and the majority of population is dependent upon land to accomplish its basic needs. Soils of hills in Nepal are fragile and soil erosion is a serious problem (Sitaula et al. 2000). It has been estimated that soil loss through surface erosion from the agricultural land in hills varies from less than $2 \mathrm{t} /$ ha/ year/ to highest soil loss of about $105 \mathrm{t} / \mathrm{ha} /$ year
(Acharya et al. 2007). Soil losses are found to be higher in bari land on sloping terraces (3.2 t /ha/ year) than in khet land (less than $1 \mathrm{t} / \mathrm{ha} /$ year). In Jumla, due to high intensity of wind, wind erosion and prevalence of erratic rain with high intensity have been accelerating gully erosion resulting loss of top layer soil and depletion of nutrients.

\section{Rice yield with respect to the effect of meteorological attributes in Jumla}

It has been found that rainfall pattern of Jumla (1995 to 2008) has almost a smooth pattern (Table 1) that coincide with the yield of rice however, after 1997 with the fluctuating rainfall the status of rice yield is also following the rainfall trend as well.

Table 1. Rice productivity with relation to rainfall pattern and temperature in Jumla from 1995 to 2008

\begin{tabular}{l|c|c|c|c|c}
\hline Year & $*$ T max $\left({ }^{\mathbf{0}} \mathbf{C}\right)$ & $* \mathbf{T} \min \left({ }^{\mathbf{0}} \mathbf{C}\right)$ & $*$ Annual rainfall (mm) & **Rice area (ha) & $\begin{array}{c}\text { ** Rice yield } \\
\mathbf{( k g} / \mathbf{h a})\end{array}$ \\
\hline 1995 & & & & 1371 & 1985 \\
1996 & 20.21 & 4.92 & 829.0 & 1350 & 2000 \\
1997 & 20.54 & 4.80 & 832.8 & 1400 & 1707 \\
1998 & 19.34 & 4.60 & 770.8 & 1450 & 1761 \\
1999 & 21.37 & 5.90 & 830.9 & 1500 & 1000 \\
2000 & 21.79 & 5.50 & 675.7 & 1835 & 1460 \\
2001 & 2.16 & 886.6 & 2800 & 1000 \\
2002 & 21.23 & 5.40 & 728.1 & 2775 & 1457 \\
2003 & 20.72 & 5.24 & 842.2 & 2800 & 1457 \\
2004 & 21.04 & 5.86 & 842.9 & 2800 & 1579 \\
2006 & 21.50 & 4.91 & 685.4 & 2850 & 1173 \\
2007 & 20.98 & 5.66 & 747.7 & 2850 & 1700 \\
\hline
\end{tabular}

Source: *Department of hydrology and meteorology, Nepal 2008/09 *MoAC , Nepal 2008/09

There has been experience of inconsistent rainfall pattern with higher intensities of rain and less number of rainy days in Jumla. This could be the effect of climate change. Such fluctuations in rainfall pattern are responsible for excessive dryness during drought and damage to the rice field during heavy down pours. These consequences have ultimately led to the problem of leaching and damage to rice field at the river side field. On the other hand, decrease in soil moisture in the sloppy area has less capacity to retain water. Basnet (2009) reported that to produce $1 \mathrm{~kg}$ rice tentatively 3,000 liter of water is required whereas to grow rice in one hectare of land it needs 800,000 liter water. In Jumla, due to erratic rainfall there is uncertainty of irrigation facility to rice cultivation. Such vagaries of rainfall and shortage of irrigation to rice are responsible for environment degradation. Raut (2010) reported that emission of methane from rice field supplied with $50 \%$ nitrogen fertilizer was $49 \mathrm{~kg} / \mathrm{ha}$ which is quite high in rainfed irrigation.

\section{Temperature and sunshine}

Rice plant is very much susceptible to temperature and it thrives fairly with temperature ranging from $20^{\circ}$ $\mathrm{C}$ to $40^{\circ} \mathrm{C}$. The optimum temperature of $30^{\circ} \mathrm{C}$ during day time and $20^{\circ} \mathrm{C}$ during night time seems to be more 
favorable for its development and growth. Rice yield has been fluctuating along with the fluctuation of temperature (Table 1). The yield of rice is influenced by the solar radiation particularly during the last 35 to 45 days of its ripening period (www.Wikipedia, 2010). The effect of solar radiation is more profound where water, temperature and nitrogenous nutrients are not limiting. But in the case of Jumla nitrogen is a limiting factor for all crops and rice is no exception because Jumla has been declared organic district in 2009 by the DDC, Jumla. Therefore, after declaration of Jumla as organic district, there is no question of applying any chemical fertilizers for the farming and rice could not be an exception until the declaration prevails. In hills because of clouds during reproductive phase of rice, for example, rice varieties Chandanath- 1 and Chandannath-3 in Jumla face less sunshine duration during the grain filling period resulting to low assimilation. However, as the crop advances there is bright sunshine during ripening period of the crop that hastens development of carbohydrates in the grains despite low temperature in high altitudes.

\section{Traditional method of rice cultivation in Jumla}

Farmers soak rice seed in water during the last week of March (12 to 15 Chaitra) for three days and dry them for two hours under shade. Thereafter the seeds are kept in jute sack, covered with woolen blanket and are kept near by a fireplace (Ageno) for four days. Sometimes soaked rice seeds are kept in the cots and sleeping mats made up of local materials such as rice straw and woolen blankets are placed over the seed and sufficient heat is provided to facilitate germination. After germination, seed are spread over seed beds which are then covered with char coal and ashes made from burnt dung cakes evenly on the seedbed to enhance temperature. This practice seems very scientific for the materials used to cover seed in the nursery beds help conserve heat sufficient to germinate the seeds.

When the rice seedlings are about two month old i.e. last week of May (second week of Jestha) single seedling/hill are randomly and closely transplanted in the spacing of about $5 \times 5-\mathrm{cm}$ hill to hill in well puddled rice field. Within two weeks transplanting is completed. Nearly in 180 days up to the last week of October (second week of Kartik) rice in Jumla is harvested this is the right time for planting barley in rice-barley cropping pattern. On the same day of rice harvesting cattle are allowed to graze on green grasses in the rice field. This also makes rice harvesting a unique system in Jumla where nearby farmers are compelled to harvest their rice on the same day otherwise cattle may graze on the plots where rice is not still harvested. Therefore, rice varieties distributed by formal seed systems, for example, Chandanath series are late maturing than that of Jumli Marshi and are affected due to forced harvesting resulting in low yield.

Compared to ten years back farmers reported that soil moisture content has been decreasing while day temperature is increasing for the same period. Therefore, the changes have occurred in the farmers' practices about rice seed priming. These days, farmers do not sleep over the seed bags of rice to warm it for germination and they have been minimizing the use of charcoal to spread over the seed under seed bed condition as well. It has been reported that due to climate change the increase in surface temperature may increase the growing season in temperate Asia, thereby prolonging the grain-filling period resulting to higher yields (Rosenzweig $\&$ Hillel 1998 as cited by IPCC).

However, in the case of Jumla, farmers opined that although the temperature has increased and higher yields are expected but due to socio-cultural reasons some of the crops are harvested prematurely because it is customary to let cattle in the rice field when crop is harvested by neighbors. As cited by Matsui \& Horie (2000) it is reported that in south central and southwestern Japan, however, rice yields are expected to decline by at least $30 \%$ because of spikelet sterility and shorter rice growing duration. For Jumla, meteorological data of 1990 to 2008 depicted that in 1998 the average minimum temperature was $6.7^{\circ} \mathrm{C}$ and average maximum temperature was $21.2^{\circ} \mathrm{C}$ which were the two extremes of the temperature during the period of 18 years. In that extreme year, rice area was increased by 50 ha but rice productivity was decreased by $54 \mathrm{~kg} /$ ha against the year 1997 in which the area was 1400 ha and the productivity was $1707 \mathrm{~kg} / \mathrm{ha}$ (Table 1). Majority of the farmers (70\%) were growing Chandanath series of rice variety which are affected by cold injury due to long growing period (more than 180 days). As a result of cold injury Chandannath series rice varieties do not get sufficient time for grain filling and there are more unfilled grains in those varieties 
because of forced harvesting due to socio-cultural reasons in Jumla conditions.

Physiologically for rice, it is reported that there is an increase in respiration in a warmer atmosphere that demands more water availability, rice yield is expected is to be declined (Wang, 1996). Therefore, scientific reason for stagnation of rice production in Jumla could be due to lack of desirable rice variety to pace with the change of climate which coherently supports the cultural norms regarding rice cultivation.

Rice cultivation in Jumla was found to be associated with socio-cultural as well as special agronomic practices. Also, Jumla is a unique place where rice is cultivated in the highest altitude of the world. Hence, this place could be an important centre for agro-tourism with respect to rice cultivation in the high altitude range of the world. Chandannath series of improved rice varieties disseminated in the regions were reported requiring long growing period of about 180 days and these have been affected with cold injury in reproductive stages of grain filling and maturity. To enhance rice production in high altitude regions of Jumla there is a need to promote early maturing (about 160 days) rice varieties similar to that of Jumli Marshi, the poplar local variety of Jumla along with adequate supply of essential plant nutrients which was hindered by declaring Jumla as organic district in 2009. Also to cope up with the effect of climate change, rice production should be tailored with advanced cultural practices supporting socio-cultural condition of Jumla region as well.

\section{Acknowledgements}

Authors would like to express their gratitude to Mr. Ram Bahadur Bhujel, Senior Scientist/Chief of the Agriculture Research Station, Vijayanagar and his support staff. They are thankful to farmer cooperators who provided their valuable information about unique system of rice production in Jumla.

\section{References}

Acharya, G.P., M.A. McDonald, B.P. Tripathi, R.M. Gardner and K. J. Mawdesley. 2007. Nutrient losses from rainfed bench terraced cultivation systems in high rainfall areas of the mid-hills of Nepal. Land Degradation Development 18:486-499

ARS. 2009. Annual Research Report. 2008/09. Agricultural Research Station, Jumla.

Basnet, B.M.S. 2009. Rice and water. In: Our heritage. Pp. 29-31.

DHM. 2009. Department of hydrology and meteorology, Nepal. 2008/09.

Goulder, L.H. and W. A .Pizer. 2006. The economics of climate change. Working paper 11923. National Bureau of Economic Research, 1050 Massachuates Avenue. Cambridge,MA02138,http:/Wikipedia foundation.org. 2010.

IPCC. 2010. Working Group II: Impacts, adaptation and vulnerability Intergovernmental panel in climate change.

Matsui and Horie. 2000. High temperarure at flowering inhibits swelling of pollen grain, a driving force for Thecae Dehiscence in Rice (Oryza sativa L.) Plant prod. Sci. 3(4):430-434.

MoAC. 2009. Statistical year book of Nepal 2008/09. Ministry of Agriculture and Cooperative, Singh Darbar, Kathmandu.

Paudel, M.N. and N.S. Thakur. 2009. Rice (Oryza sativa) in Nepalese agriculture. Hamro Sampada (Nepali) 10: 84-86.

Raut , N., B. K. Sitaula and R.M. Bajracharya. 2010. Agricultural intensification:linking with livelihood improvement and environmental degradation in mid hills of Nepal. The Journal of Agriculture and Environment 11: 83-92.

Sigdel, M. 2006 .Climate variability and its role in crop yield in central Himalaya. Central Department of Hydrology and Meteorology, Tribhuvan University, Kirtipur. Kathmandu.

Sitaula, B. K., R. P. Neupane, G.S. Paudel, P.L. Sankhyan and B.R.Singh. 2000. Land degradation in the Himalayan region: An interdisciplinary approach for analyzing system behaviour. In: Geomedical problems in developing countries.(Ed. J.Lag). Pp. 193-208.

Wang, 1996, Dai. 1997. Climate change and impact on agriculture. http://www.google.com.np. 
Nepal Journal of Science and Technology 11 (2010) 57-62 